\title{
Impact of energy storage system on the point of common coupling of the distribution network containing photovoltaic plant
}

\author{
Hua $\mathrm{Li}^{1}{ }^{*}$, Xiaohai Wang ${ }^{2}$, Wenyi $\mathrm{Li}^{1}$, Baiqing $\mathrm{Yin}^{3}, \mathrm{Yu} \mathrm{Xu}$ \\ ${ }^{1}$ Inner Mongolia electric power (group) co. LTD. Postdoctoral workstation, Hohhot 010000, China \\ ${ }^{2}$ School of Electric Power College, Inner Mongolia University of Technology, Hohhot 010051, China \\ ${ }^{3}$ Inner Mongolia electric power research institute, Hohhot 010020, China
}

Corresponding Author Email: lihua0806@qq.com

https://doi.org/10.18280/ijht.360316

Received: 7 February 2018

Accepted: 28 April 2018

Keywords:

photovoltaic/energy storage (PV/ES)

system, Real time digital simulator

(RTDS), point of common coupling

$(P C C)$, temperature, effective voltage

\begin{abstract}
This paper attempts to disclose the effects of the access of energy storage system on the fluctuations of power and voltage at the point of common coupling (PCC) in distribution networks containing photovoltaic (PV) plants. For this purpose, a photovoltaic/energy storage (PV/ES) power generation model was established and the variations in PCC power and voltage before and after the access of the energy storage system were simulated at different temperatures, access positions and capacities. Besides, the decrease in PCC voltage fluctuations was quantified according to the standard deviation of effective voltage. The simulation results reveal that the access of the energy storage system can effectively suppress the PCC voltage and power fluctuations caused by ambient temperature variation, and thus improve the PCC power quality; the same energy storage system has slightly different suppression effects on PCC voltage fluctuations depending on the access position of the PV plant and PV/ES system; the PCC voltage resistance grows significantly with the capacity expansion of the energy storage system. The research findings shed new light on the access of energy storage system to distribution networks containing PV plants.
\end{abstract}

\section{INTRODUCTION}

Photovoltaic (PV) power generation is sensitive to thermodynamic temperature and other factors. Therefore, the largescale access of distributed PV power has a negative impact on the distribution network, especially its ability to absorb PV power [1-2]. In the traditional distribution network, the temporal variation of active and reactive loads will cause voltage fluctuation, which is more violent near the end of the network. In the distribution network containing PV power, the power and voltage also change with the active and reactive loads [3]; however, the power and voltage at the point of common coupling (PCC) may vary with temperature, network structure (access position, photovoltaic [4]/energy storage (PV/ES) capacity, etc.) and other macroscopic thermodynamic states. There are many ways to tackle the power and voltage fluctuations at the PCC. One of the viable options is the introduction of the energy storage system. This method can effectively supress the temperature-induced fluctuations, enhance the ability of the network to absorb PV power, and improve the PCC power quality of PV power stations [5]. Below is a brief review of other approaches to control the variation in PCC power and voltage.

Reference [6] employs the performance quantification (PQ) method for the grid access of PV and energy storage micropower supplies, and realises dynamic control and adjustment of the grid-connected operation energy of micro networks containing PV power. Reference [7] analyses the mechanism of PCC voltage change caused by the grid access of distributed PV power and puts forward a systematic control plan for active/reactive voltage regulation of the distributed
PV power generation system with energy storage, which effectively solves the PCC voltage quality problems arising from the sudden change of PV output, the switch of large capacity load, and the interference of the distribution network. Targeting the effect of large PV plants on PCC voltage stability, Reference [8] discusses the static voltage stability of large PV plants. References [9-11] propose centralized and segmented control methods for PV power fluctuations using energy storage. References [12-15] explore the energy storage control in PV/ES systems, the design of inverter controller, and the voltage regulation methods for PV power distribution networks. Despite the fruitful results on the fluctuation control for PV power stations, the above studies neither pinpoint the influencing factors of the fluctuations (e.g. the impacts of access position, capacity and environmental conditions on PCC power and voltage fluctuations) nor quantify the contribution of energy storage to the suppression of voltage fluctuations.

Based on real time digital simulator (RTDS), this paper takes an actual PV power station in Inner Mongolia, China, as an example to analyse the impacts of the access position and capacity of the PV/ES system and the temperature on the PCC power and voltage fluctuations. Meanwhile, the degree of impacts from energy storage on PCC voltage fluctuations was characterized by the standard deviation of effective voltage. 


\section{MODELLING OF PV/ES POWER GENERATION SYSTEM}

\section{1 mathematical model of pv module}

The mathematical model of the PV module is shown in Figure 1, where the equivalent current Is flows into the inverter via the series equivalent resistance Rs. Following the basic principle of PV power generation, the circuit in the figure accurately depicts the voltage and current features of the PV cell [16].

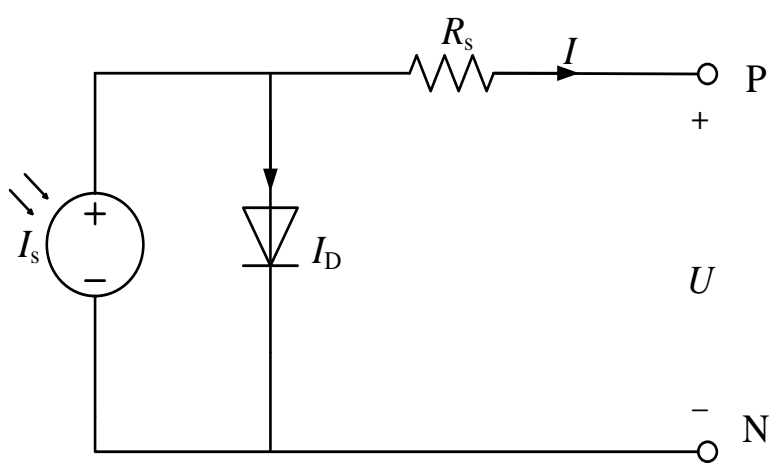

Figure 1. Mathematical model of PV module

In Figure 1, the current flowing through the diode ID can be calculated as:

$$
I_{\mathrm{D}}=I_{\mathrm{o}}\left[\exp \left(\frac{U+I \cdot R_{\mathrm{S}}}{n \cdot U_{T}}\right)-1\right]
$$

where I0 is the saturation current of the diode; $\mathrm{n}$ is an ideal factor; UT is the thermal voltage of the PV cell; $\mathrm{U}+\mathrm{I} \cdot \mathrm{Rs}$ is the voltage across the diode. The parameters UT and I0 can be obtained by the following equations:

$U_{T}=\left[(T+273) \cdot \frac{\mathrm{k}}{\mathrm{q}}\right] \cdot N_{C}$

$I_{0}=A \cdot(T+273)^{\gamma} \cdot \exp \left(\frac{E_{\mathrm{g}} \cdot N_{c}}{n \cdot U_{T}}\right)$

where $\mathrm{T}$ is the Celsius temperature $(1.380650 \times 10-23 \mathrm{~J} / \mathrm{K})$; $\mathrm{k}$ is the Boltzmann constant; $\mathrm{q}$ is the amount of electric charge $(1.602176 \times 10-19 \mathrm{C})$; $\mathrm{Nc}$ is the number of $\mathrm{PV}$ cell components; $\gamma$ is the temperature influencing factor; $\mathrm{Eg}$ is the band gap of the semiconductor material; $\mathrm{A}$ is the temperature coefficient of the saturation current. The value of A can be obtained from equations (4) and (5) below.

$$
\begin{gathered}
E_{\mathrm{g}}=1.16-0.000702 \cdot \frac{(T+273)^{2}}{(T+273-1108)} \\
A=\frac{I_{0 \mathrm{ref}}}{\left(T_{\mathrm{ref}}+273\right)^{\gamma} \cdot \exp \left(\frac{-E_{\mathrm{gref}} \cdot N_{c}}{n \cdot U_{\text {ref }}}\right)}
\end{gathered}
$$

$$
I_{\text {Oref }}=\frac{I_{\text {scref }}}{\exp \left(\frac{U_{\text {ocref }}}{n \cdot U_{\text {Tref }}}\right)-1}
$$

$R_{\mathrm{s}}=\frac{n \cdot U_{T \mathrm{ref}} \cdot \ln \left(\frac{I_{\text {scref }}-I_{\mathrm{mpref}}}{I_{0 \mathrm{ref}}}+1.0\right)-U_{\mathrm{mpref}}}{I_{\mathrm{mpref}}}$

$I_{\mathrm{sc}}=I_{\text {scref }} \cdot\left(\frac{S}{1000}\right) \cdot\left[1.0+\frac{J_{T}}{100} \cdot\left(T-T_{\mathrm{ref}}\right)\right]$

In equations (6)-(8), I0ref is the reference saturation current of the diode; Isc is the short-circuit current; $\mathrm{S}$ is the actual input light intensity; JT is the temperature coefficient of the short-circuit current.

\subsection{Equivalent model of lithium battery}

The energy storage system mainly consists of a lithium battery, an inverter, a control device, and a transformer. The equivalent circuit model of the lithium battery is presented in Figure 2. The main performance parameters are the output DC voltage Uoc and state of charge (SOC) [17].

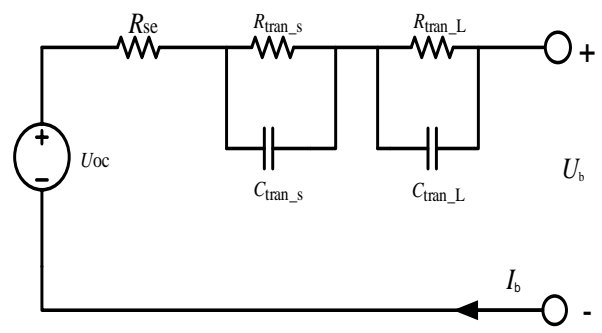

Figure 2. Equivalent circuit of lithium battery

The parameters in Figure 2 are all functions of the SOC. In the simulation model, $S O C$ equals $50 \%$; $R_{\text {trans_s }}$ and $C_{\text {trans } s}$ represent the short-term transient resistance and capacitance of the battery, respectively; $R_{\text {trans_ } L}$ and $C_{\text {trans } L}$ represent the short-term transient resistance and capacitance of the battery, respectively. These parameters can be expressed as:

$U_{O C}(S O C)=-1.031 \cdot e^{-35.5 O C}+3.685+0.2156 \cdot S O C-0.1178 \cdot S_{O C C}^{2}+0.3201 \cdot S_{O C C}^{3}(9)$

$R_{\mathrm{se}}(S O C)=0.1562 \cdot 2^{-24.37 \cdot s o c}+0.07446$

$R_{\text {tran_s }}(S O C)=0.3208 \cdot \mathrm{e}^{-29.14 \cdot s o c}+0.04669$

$C_{\text {tran } \_s}(S O C)=-752.9 \cdot \mathrm{e}^{-13.51 \cdot s o c}+703.6$

$R_{\text {tran_L }}(S O C)=6.603 \cdot \mathrm{e}^{-155.2 \cdot s o c}+0.04984$

$C_{\text {tran } \_\mathrm{L}}(S O C)=-6056 \cdot \mathrm{e}^{-27.12 \cdot s o c}+4475$ 


\subsection{Block diagram of PV/ES system}

As shown in Figure 3, the PV power station is the generation unit, the load is the consumption unit, the control device is the management unit, the energy storage is either a generation unit or consumption unit depending on the load and the grid-side power demand.

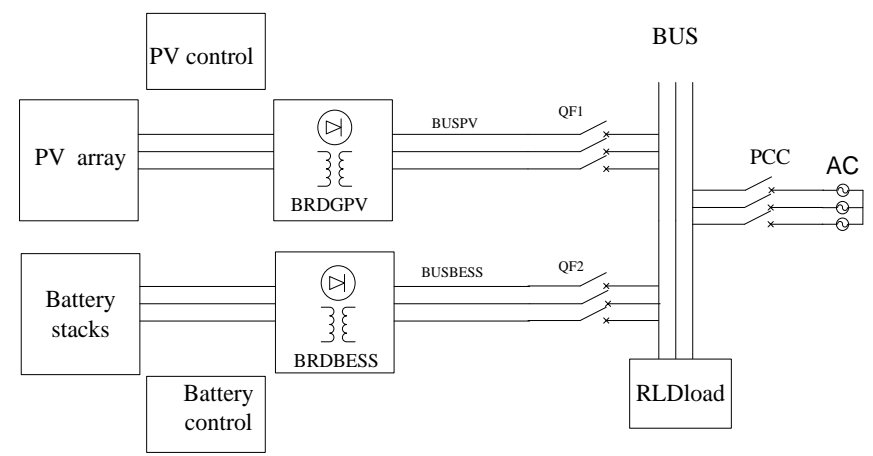

Figure 3. Block diagram of PV/ES system

\section{CONTROL STRATEGY FOR PV POWER GENERATION SYSTEM}

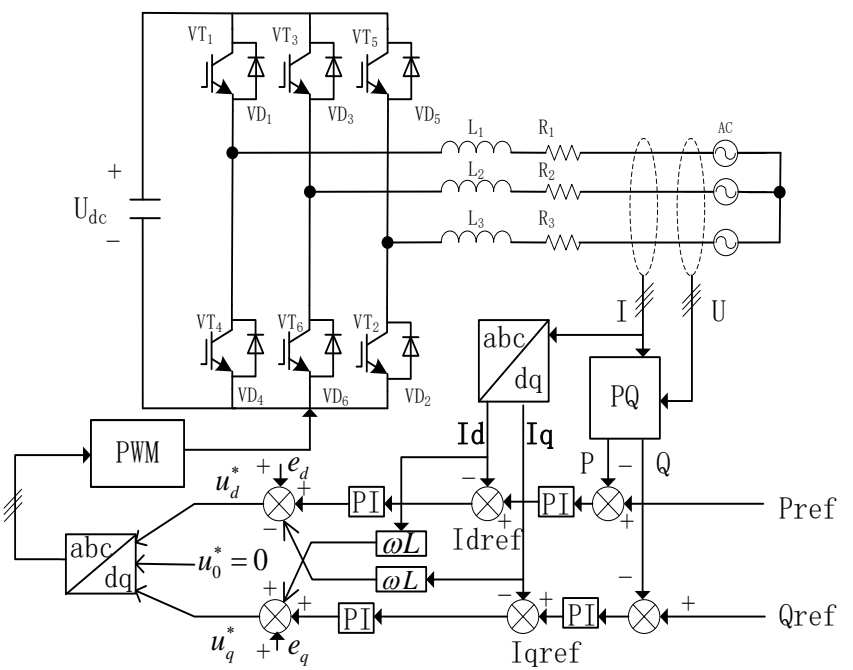

Figure 4. PQ control strategy

The PQ control strategy is illustrated in Figure 4. In the grid-connected mode, all PV systems adopt the control structure in which the power is in the outer loop and the gridconnected current is in the inner loop. Note that AC is the grid equivalent power supply. The power outer loop needs to collect the grid voltage $u$ and the grid-connected current i. On this basis, the measured power can be obtained by the PQ calculation module. Based on the differences between the measured power and the given values Pref and Qref, the given values Idref and Iqref for the inner loop can be derived via proportional-integral (PI) compensation. Through the coordinate transform, it is possible to determine the currents Id and Iq on axis $\mathrm{d}$ and axis q, respectively. Based on the differences between the currents and Idref and Iqref, the reference voltages $\mathrm{u}^{*} \mathrm{~d}$ and $\mathrm{u}^{*} \mathrm{q}$ can be obtained via PI compensation and the feedforward decoupling. Finally, the turn-on and turn-off signals of the switch tube can be derived through inverse coordinate transformation and pulse-width modulation (PWM), ensuring that the inverter delivers the required power to the grid according to the pre-set power [18].

\section{SIMULATION ANALYSIS}

Taking an actual PV power station in Inner Mongolia, China, as an example, the author created a simulation model for the access of the PV/ES system into the IEEE9 distribution network. Specifically, the PV plant has a capacity of $10 \mathrm{MW}$, the lithium battery pack has a capacity of $6 \mathrm{MW}$, and a $220 \mathrm{kV}$ booster station was connected to a $35 \mathrm{kV}$ medium voltage network at node 6 . The wiring diagram of the example system is shown in Figure 5 [19].

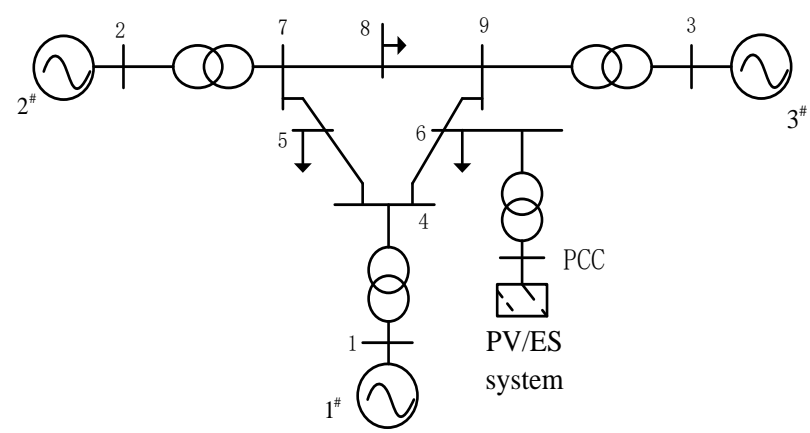

Figure 5. Wiring diagram of the example system

In the RTDS simulation model, the default light intensity was set to $1,000(\mathrm{w} / \mathrm{m} 2)$, the temperature to $25^{\circ} \mathrm{C}$, and the initial active demand of the load is $5 \mathrm{~kW}$. Figure 6 displays the active power of the PV plant (PVs) and that of the PCC (PDG) before and after the grid access of the energy storage system.

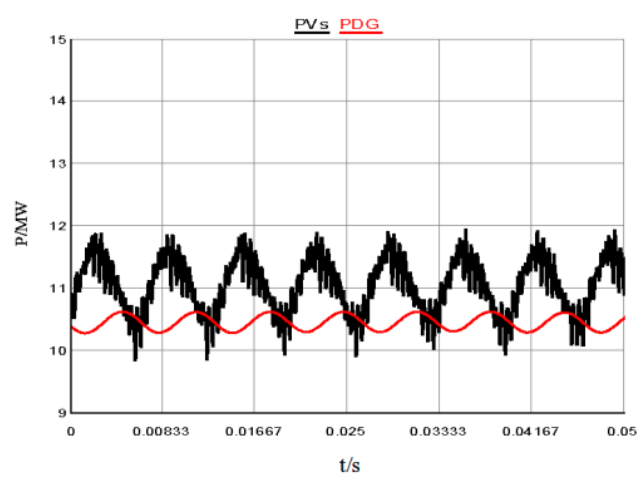

(a) Before the access

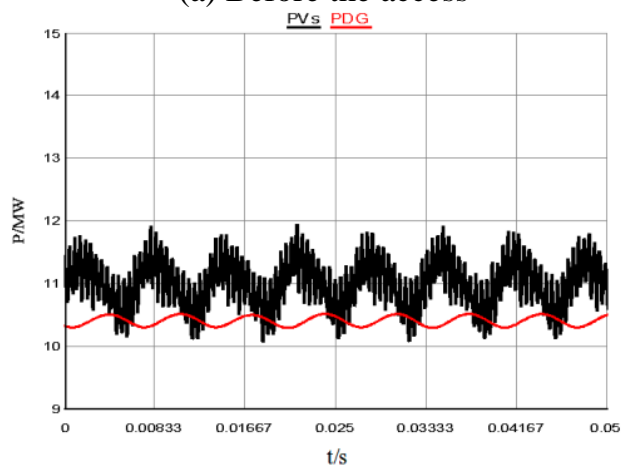

(b) After the access

Figure 6. Active power of PV plant and PCC 
The PCC voltage waveform and the effective voltage waveform are presented in Figure 7 . The effective voltage at the PCC was selected to represent the voltage fluctuations, and its standard deviation was adopted to quantify the stabilizing effect of the energy storage system. This is because the voltage fluctuations cannot be demonstrated by three-phase AC voltage. According to the waveform changes before and after the access of the energy storage system, the PCC voltage fluctuated much less violently after the access, while the peak and valley points were flattened.

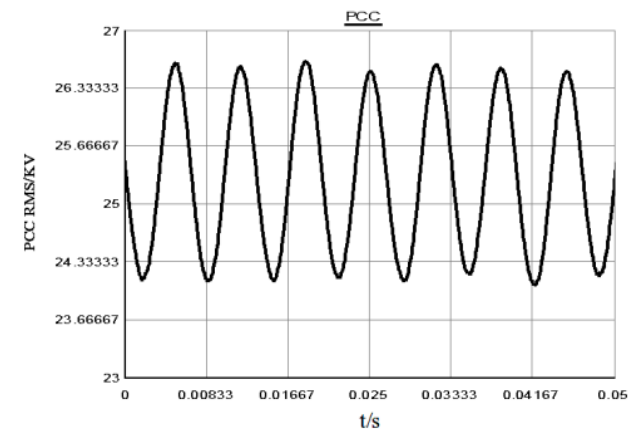

(a) Before the access

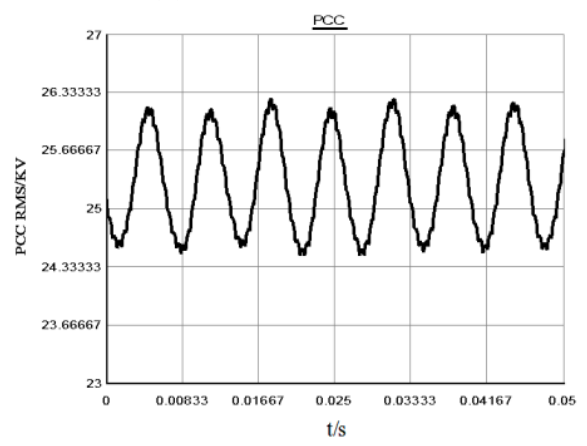

(b) After the access

Figure 7. PCC voltage waveform and the effective voltage waveform

\subsection{Effects of ambient temperature}

(1) Decrease of ambient temperature

When the ambient temperature suddenly fell from $25^{\circ} \mathrm{C}$ to $0^{\circ} \mathrm{C}$, the active power of $\mathrm{PV}$ plant and PCC fluctuated violently. After the access of the energy storage system, the PCC power fluctuated much less violently and stabilised after a few oscillations for $0.03 \sim 0.06 \mathrm{~s}$. The waveforms of the active power are shown in Figures 8(a) and (b).

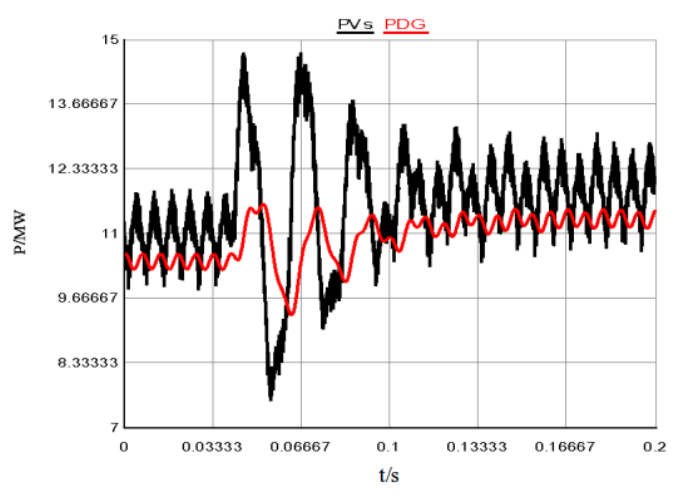

(a) Before the access

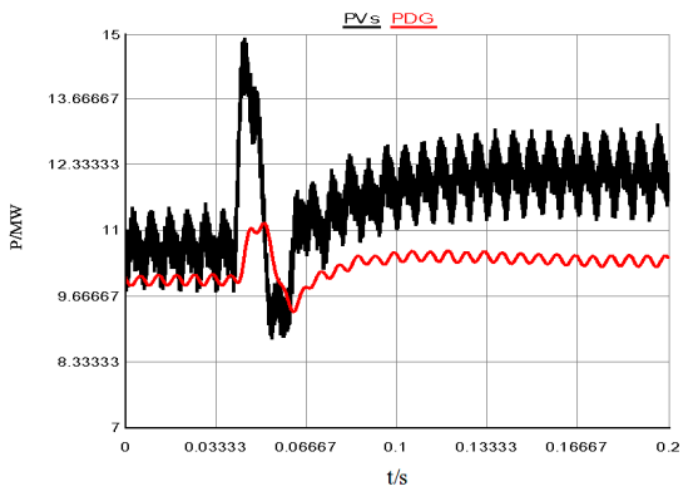

(b) After the access

Figure 8. Active power waveforms of PV plant and PCC with the decrease of ambient temperature

Figure 9 shows the waveform of PCC effective voltage with the decrease of ambient temperature. As can be seen from the simulated waveforms in Figures 9(a) and (b), the access of the energy storage system effectively reduced the duration and amplitude of PCC voltage fluctuations and significantly improved the quality of PCC power.

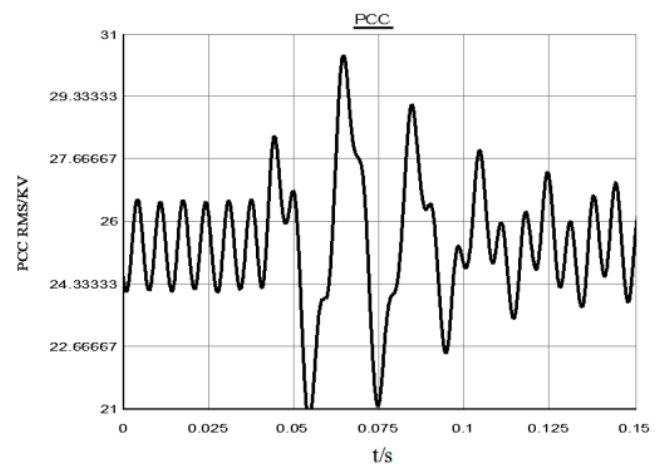

(a) Before the access

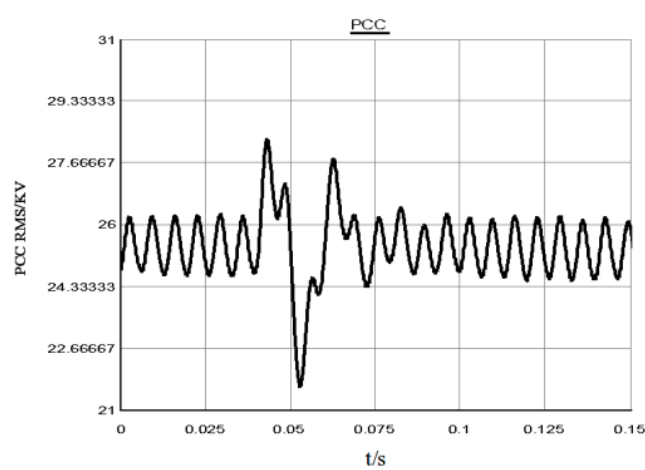

(b) After the access

Figure 9. Effective voltage waveform of the PCC with the decrease of ambient temperature

(2) Increase of ambient temperature

When the ambient temperature suddenly rose from $25^{\circ} \mathrm{C}$ to $30^{\circ} \mathrm{C}$, the active power of PV plant and PCC fluctuated slightly (Figure 10). After the access of the energy storage system, the PCC active power fluctuated less violently but the stabilisation effect was not very prominent. This trend is mainly attributed to the small temperature difference. 


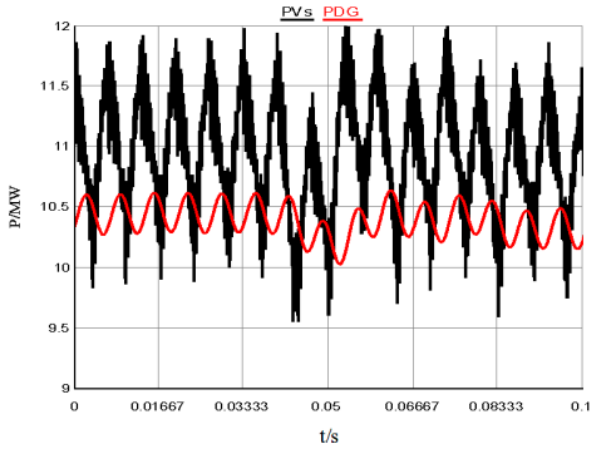

(a) Before the access

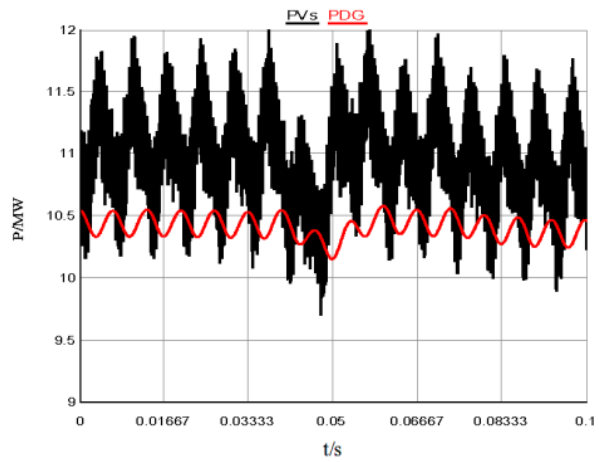

(b) After the access

Figure 10. Active power waveforms of PV plant and PCC with the increase of ambient temperature

Figure 11 shows the waveform of PCC effective voltage with the increase of ambient temperature. It can be seen that the access of the energy storage system significantly suppressed the amplitude of PCC voltage fluctuations. Thus, the energy storage system helps stabilise the PCC voltage oscillation caused by rising temperature and effectively improve the PCC power quality

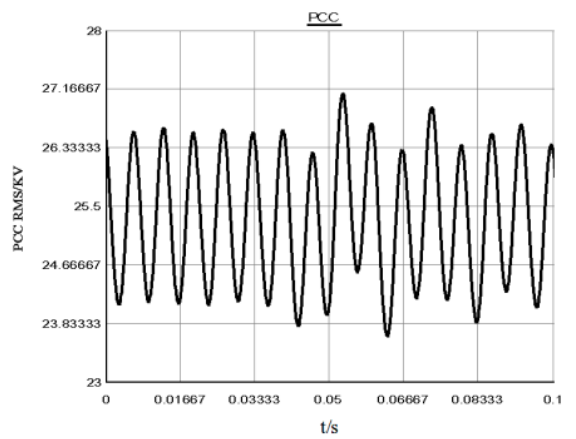

(a) Before the access

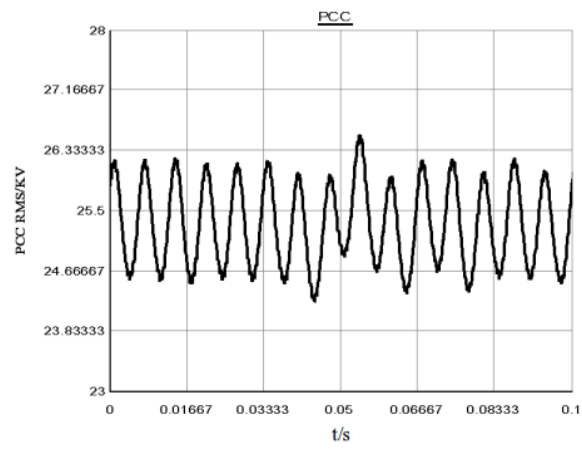

(b) After the access

Figure 11. Effective voltage waveform of the PCC with the increase of ambient temperature
Standard deviation measures how dispersed the average value of a set of data. It is positively correlated with the difference between most values and their average value. Hence, the standard deviation of the voltage can accurately reflect the voltage fluctuations. The standard deviations of the PCC effective voltages in the previous simulations are listed in Table 1.

Table 1. Standard deviations of effective voltages

\begin{tabular}{cccccc}
\hline $\begin{array}{c}\text { Influencin } \\
\text { g factor }\end{array}$ & $\begin{array}{c}\text { Transie } \\
\text { nt } \\
\text { variatio } \\
\mathrm{n}\end{array}$ & $\begin{array}{c}\text { Before } \\
\text { the } \\
\text { access }\end{array}$ & $\begin{array}{c}\text { After } \\
\text { the } \\
\text { access }\end{array}$ & $\begin{array}{c}\text { Differenc } \\
\mathrm{e}\end{array}$ & $\begin{array}{c}\text { Increas } \\
\mathrm{e}(\%)\end{array}$ \\
\hline & $25-0$ & 1.46627 & $\begin{array}{c}0.94710 \\
2\end{array}$ & 0.519168 & $\begin{array}{c}35.41 \\
\%\end{array}$ \\
$\begin{array}{c}\text { Ambient } \\
\text { temperatur } \\
\mathrm{e}\left({ }^{\circ} \mathrm{C}\right)\end{array}$ & $25-30$ & $\begin{array}{c}0.86823 \\
6\end{array}$ & $\begin{array}{c}0.56128 \\
2\end{array}$ & 0.306954 & $\begin{array}{c}35.35 \\
\%\end{array}$ \\
\hline
\end{tabular}

As can be seen from Table 1, when the ambient temperature suddenly fell from $25^{\circ} \mathrm{C}$ to $0^{\circ} \mathrm{C}$, the access of the energy storage could reduce the PCC voltage fluctuations by about $35.41 \%$; when the ambient temperature suddenly rose from $25^{\circ} \mathrm{C}$ to $30^{\circ} \mathrm{C}$, the reduction of PCC voltage fluctuations grew to $35.35 \%$. This means the energy storage system has a major suppression effect on the transient PCC voltage fluctuations induced by temperature variation.

\subsection{Effects of access position}

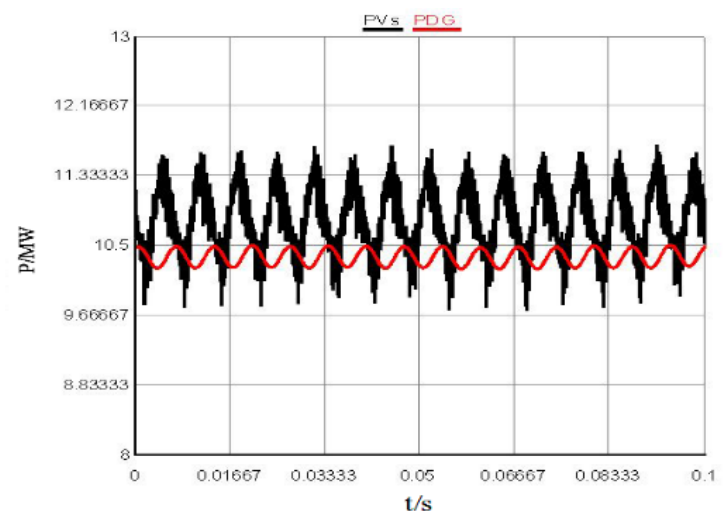

(a) Before the access

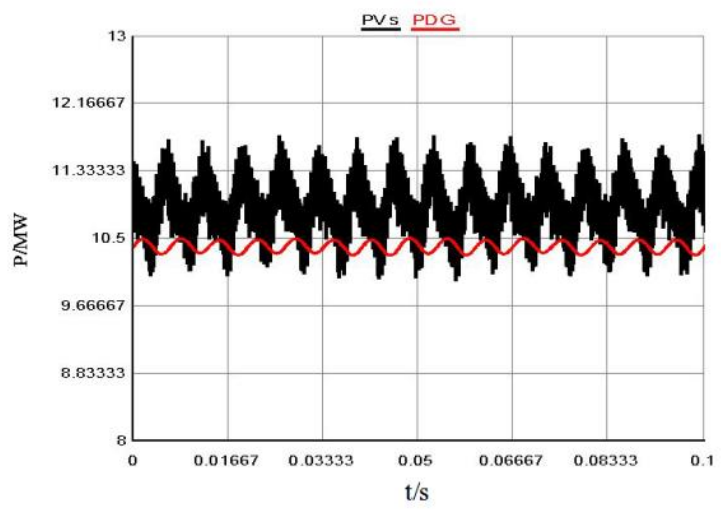

(b) After the access

Figure 12. Active power of PV plant and PCC under node 3 access 


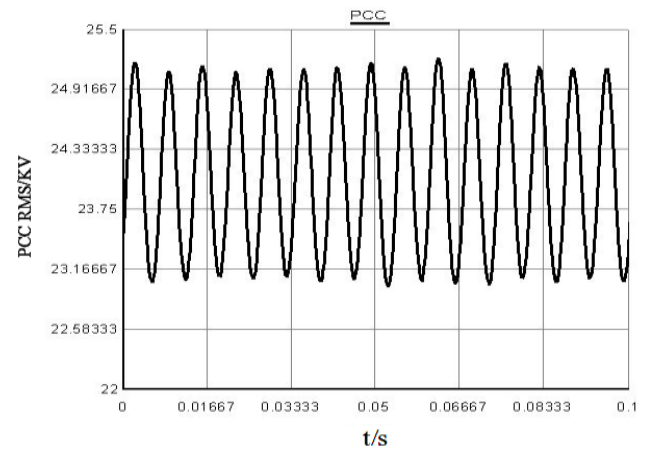

(a) Before the access

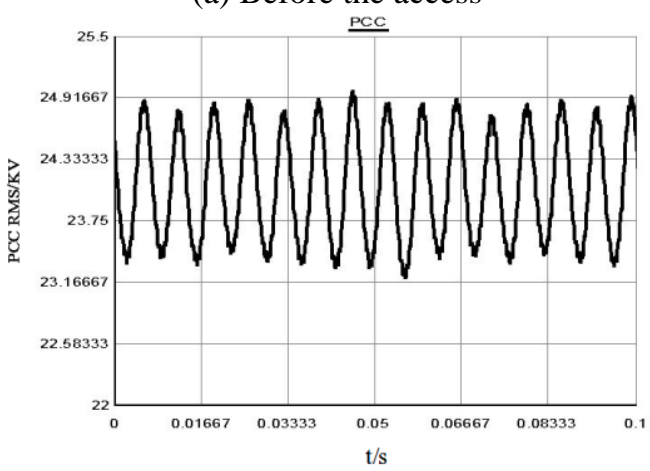

(b) After the access

Figure 13. PCC effective voltage under node 3 access

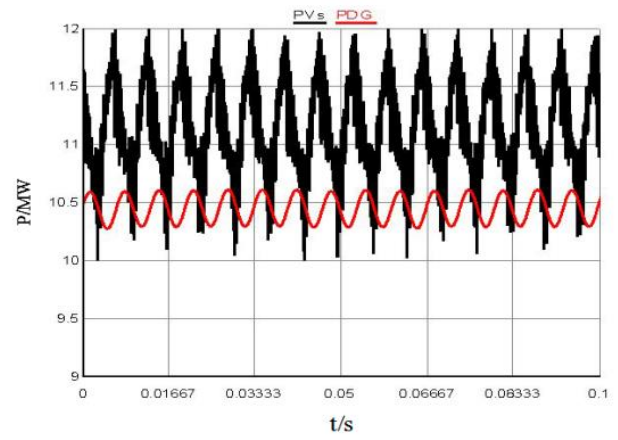

(a) Before the access

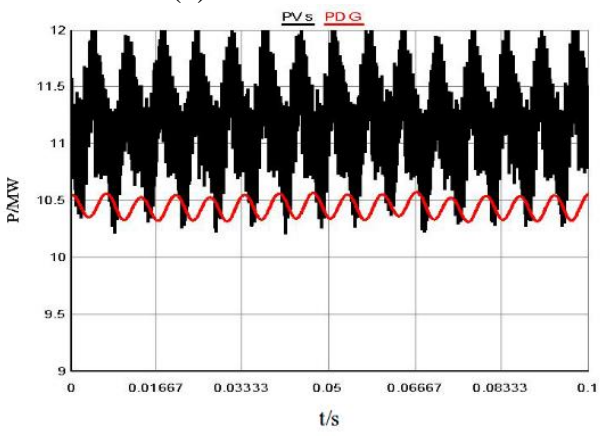

(b) After the access

Figure 14. Active power of PV plant and PCC under node 4 access

When a PV plant is connected to the IEEE9 standard test distribution network, the network structure and PCC effective voltage will vary with the access positions. In light of this, node 3 , node 4 and node 8 were selected to analyse the effects of energy storage system on the fluctuations of PCC power and effective voltage. Then, the suppression effect of the energy storage system on the voltage fluctuations was quantified according to the standard deviations of PCC effective voltage at different nodes.

(1) Node 3 access

When the PV plant and PV/ES system were accessed at node 3 , the active power of the plant (PVs) and the PCC (PDG) were plotted. As shown in Figure 12, the fluctuations of PCC active power were suppressed to a limited degree after the access of the energy storage system. There are two possible reasons: (1) the capacity of the IEEE9 distribution network far exceeds that of energy storage; (2) the PCC power has reached the stable state in normal conditions, such that no obvious power exchange occurs after the access.

Figure 13 shows the fluctuations of PCC effective voltage under node 3 access. As shown in Figure 13(b), the postaccess PCC effective voltage fluctuated much less violently and stabilised within $23.17 \sim 24.92 \mathrm{kV}$, indicating that the application of the energy storage system can effectively stabilise PCC voltage and improve PCC power quality.

(2) Node 4 access

When the PV plant and PV/ES system were accessed at node 4, the active power of the plant (PVs) and the PCC (PDG) were plotted. As shown in Figure 14, the fluctuations of PCC active power were suppressed by a certain extent.

Figure 15 shows the fluctuations of PCC effective voltage under node 4 access. Comparing the waveforms in Figures 15(a) and (b), it is clear that the access of the energy storage system can stabilise the PCC effective voltage, reduce the amplitude of voltage fluctuations and improve the quality of PCC output power of the PV plant.

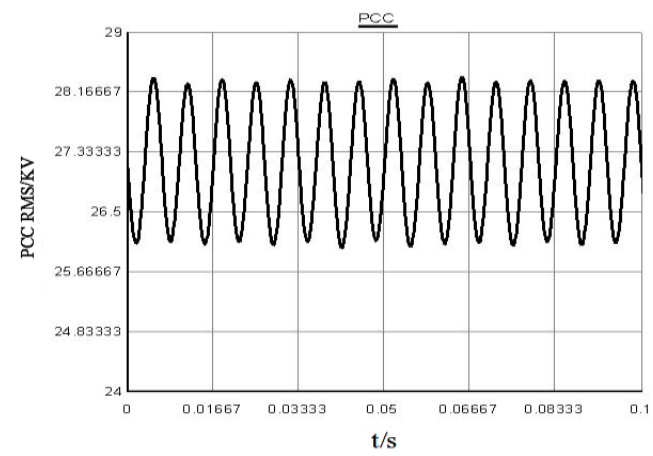

(a) Before the access

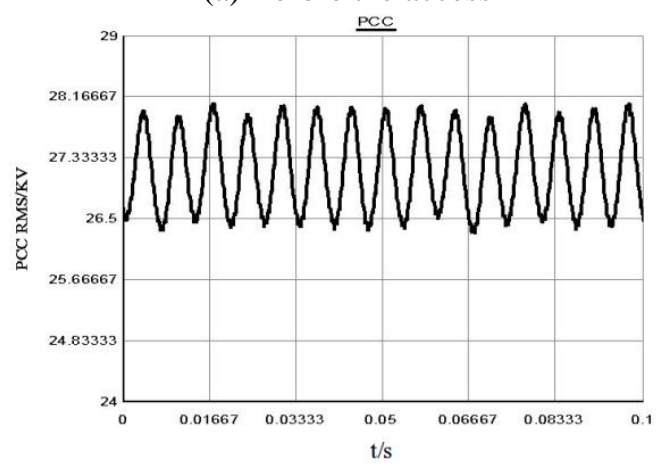

(b) After the access

Figure 15. PCC effective voltage under node 4 access

(3) Node 8 access

When the PV plant and PV/ES system were accessed at node 8 , the active power of the plant (PVs) and the PCC (PDG) were plotted. As shown in Figure 16, the fluctuations 
of PCC active power were also suppressed to a limited degree after the access of the energy storage system.

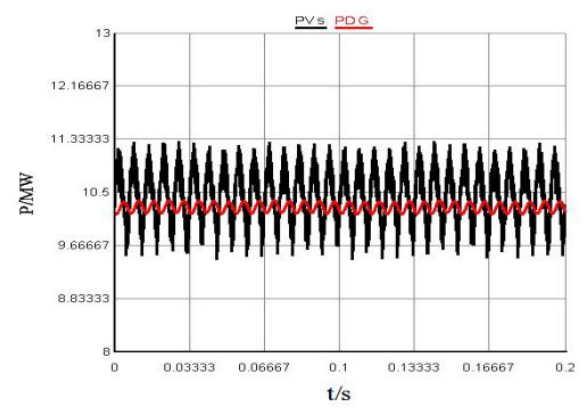

(a) Before the access

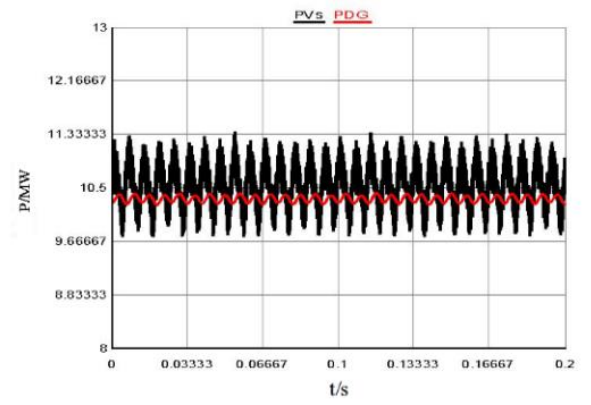

(b) After the access

Figure 16. Active power of PV plant and PCC under node 8 access

Figure 15 shows the fluctuations of PCC effective voltage under node 8 access. It can be seen that the effective voltage fluctuated less violently, as evidenced by the $0.3 \mathrm{kV}$ decrease of fluctuation amplitude.

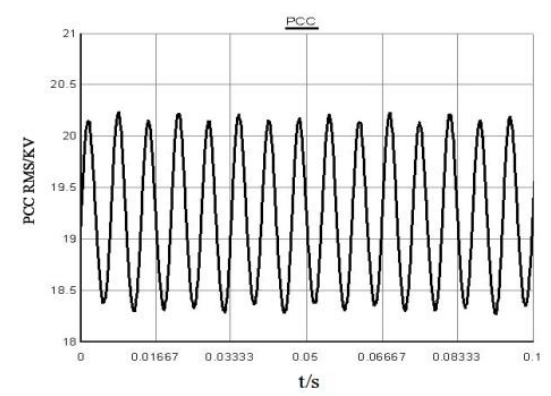

(a) Before the access

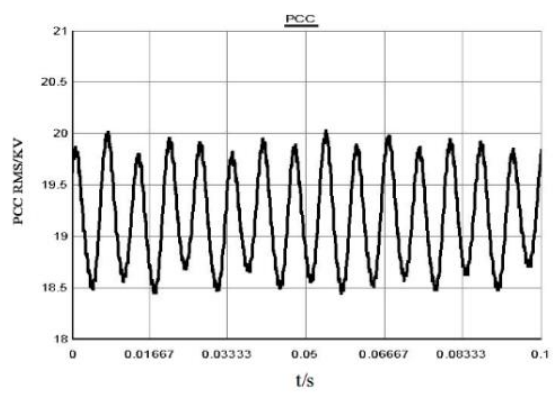

(b) After the access

Figure 17. PCC effective voltage under node 8 access

(4) Analysis on standard deviations of PCC effective voltage at different access positions

Table 2 lists the data on the standard deviations of PCC effective voltage when the PV plant and PV/ES system are accessed at different nodes. The results show that the access of the energy storage system effectively stabilised PCC voltage fluctuations, and the suppression effect of the same system varied by a margin of $3.85 \%$.

Table 2. Standard deviations of PCC effective voltage at different access positions

\begin{tabular}{ccccc}
\hline $\begin{array}{c}\text { Access } \\
\text { position }\end{array}$ & $\begin{array}{c}\text { Before the } \\
\text { access }\end{array}$ & $\begin{array}{c}\text { After the } \\
\text { access }\end{array}$ & Difference & $\begin{array}{c}\text { Increase } \\
(\%)\end{array}$ \\
\hline Node 3 & 0.739998 & 0.516084 & 0.223914 & 30.26 \\
Node 4 & 0.806142 & 0.548694 & 0.257448 & 31.94 \\
Node 8 & 0.65607 & 0.47177 & 0.1843 & 28.09 \\
\hline
\end{tabular}

\subsection{Effects of PV/ES capacity}

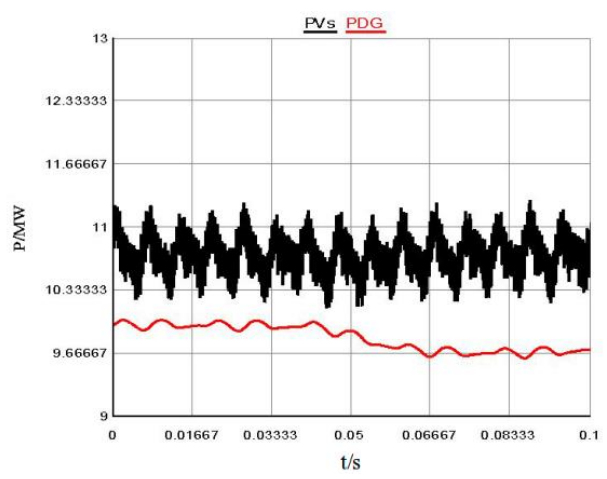

Figure 18. Active power of PV plant and $\mathrm{PCC}$ at 10:1.5(MW)

The PCC effective voltage at 10:1.5(MW) was shown in Figure 19. It can be inferred that the PCC effective voltage dropped to $21.46 \mathrm{kV}$.

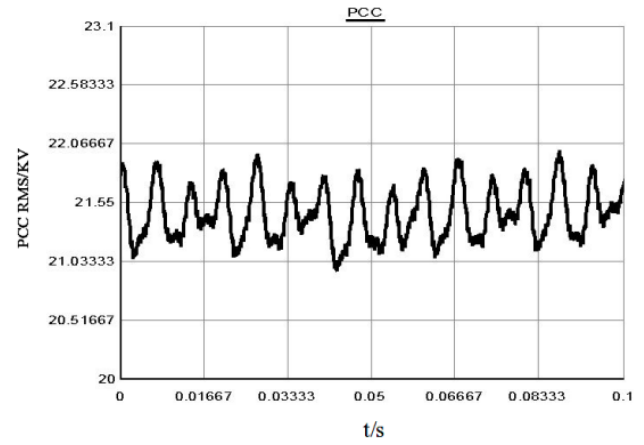

Figure 19. PCC effective voltage at 10:1.5(MW)

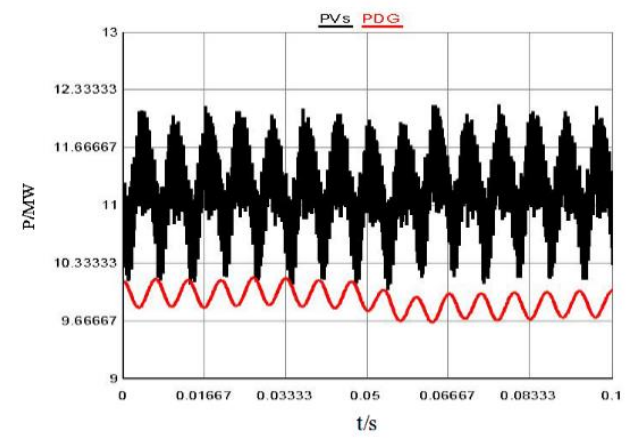

Figure 20. Active power of PV plant and PCC at 10:10(MW) 
Then, the PV plant capacity was set to $10 \mathrm{MW}$, the energy storage capacity was also set to $10 \mathrm{MW}$, and the PV/ES capacity was set to $10: 10(\mathrm{MW})$ [20-22]. Figure 19 records the active power of PV plant and PCC when the active load suddenly changed from $0.5 \mathrm{MW}$ to $1 \mathrm{MW}$. It can be seen that the PCC active power PDG decreased after the sudden change. Compared with Figure 18, the amplitude of active power fluctuations declined thanks to the capacity growth of the energy storage system.

The PCC effective voltage at 10:20(MW) was shown in Figure 21. It can be inferred that the PCC effective voltage at this ratio was $25.93 \mathrm{kV}$. Compared to Figure 19, it can be concluded that the capacity expansion of the energy storage system leads to significant growth in effective voltage and the ability to withstand voltage.

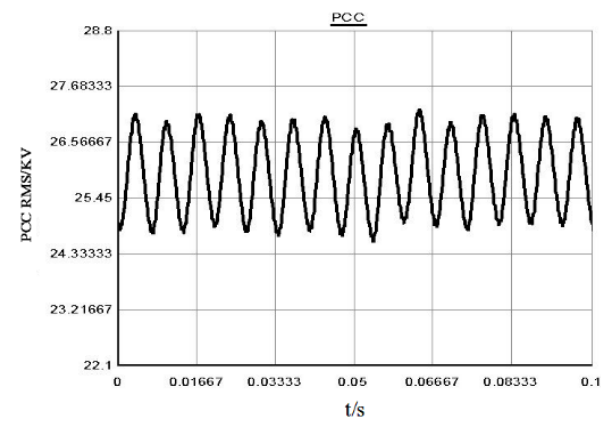

Figure 21. PCC effective voltage at 10:10 (MW)

Table 3 lists the standard deviation of active power, effective voltage and standard deviation of effective voltage of the PCC at different capacities of the PV/ES system.

Table 3. Standard deviations of PCC active power, effective voltages and standard deviations of effective voltage at different PV/ES capacities

\begin{tabular}{cccc}
\hline $\begin{array}{c}\text { PV/ES } \\
\text { capacity } \\
(\mathrm{MW})\end{array}$ & $\begin{array}{c}\text { Standard } \\
\text { deviations of PCC } \\
\text { active power }\end{array}$ & $\begin{array}{c}\text { Standard } \\
\text { deviation of } \\
\text { effective voltage }\end{array}$ & $\begin{array}{c}\text { Effective } \\
\text { voltage } \\
(\mathrm{kV})\end{array}$ \\
\hline $10: 10$ & 0.122652 & 0.773162 & 25.9353 \\
$10: 6$ & 0.0880527 & 0.498018 & 24.5675 \\
$10: 1.5$ & 0.112636 & 0.239785 & 21.4618 \\
\hline
\end{tabular}

The data in Table 3 demonstrate the significant improvement of voltage resistance with the expansion of energy storage capacity at the sudden increase of active power. When the PV/ES capacity was 10:10(MW), the effective voltage reached $25.9353 \mathrm{kV}$. Meanwhile, the voltage fluctuated greatly due to the growth in effective voltage. The fluctuations of active power were minimum (0.0880527) when the PV/ES capacity was of the initial value, i.e. 10:6(MW).

\section{CONCLUSIONS}

Considering that the thermodynamics theory is concerned with the overall pattern of a system, this paper attempts to disclose the effects of the access of energy storage system on the fluctuations of PCC power and voltage in distribution networks containing PV plants. Specifically, the decrease in PCC voltage fluctuations was quantified according to the standard deviation of effective voltage. Then, the variations in PCC power and effective voltage were analysed before and after the access of the energy storage system at the changes of temperature, an index of macro thermodynamic state. Meanwhile, the suppression effects of the same energy storage system on the PCC voltage fluctuations were compared when the PV plant and PV/ES system were accessed at different nodes. Moreover, the fluctuations in PCC power and effective voltage were discussed at different capacities of the PV/ES system. Through the analysis, the following conclusions were derived: (1) The proposed models can accurately reflect how the access of the energy storage system influences the PCC power and voltage of the distribution network containing PV plant at different access positions, different capacities, and different temperatures. (2) The access of the energy storage system can effectively suppress the PCC voltage and power fluctuations caused by ambient temperature variation, and thus improve the PCC power quality. (3) The same energy storage system has slightly different suppression effects on PCC voltage fluctuations depending on the access position of the PV plant and PV/ES system. (4) The PCC voltage resistance grows significantly with the capacity expansion of the energy storage [23] system.

\section{REFERENCES}

[1] Zeng M, Yang YQ, Li YF, Zeng B, Cheng J, Bai X. (2016). The preliminary research for key operation mode and technologies of electrical power system with renewable energy sources under energy internet. Proceedings of the CSEE (3): 681-691. http://dx.doi.org/10.13334/j.0258-

8013.pcsee.2016.03.011

[2] Li LK, Wang JH, Sun GH, Zhang X. (2016). Peak load shifting control strategy for energy storage system of $\mathrm{pv}$ micrigrid system. Modern Electric Power 33(2): 27-32. http://dx.doi.org/10.19725/j.cnki.10072322.2016.02.005

[3] Chen W, Ai X,Wu T, Liu H. Influence of Gridconnected Photovolatic System On Power Network. http://dx.doi.org/10.3969/j.issn.1006-6047.2013.02.005.

[4] Zuo B. (2018). Simulation analysis and experiment on energy transfer characteristics of photovoltaic energydriven ice storage air conditioning system. Chemical Engineering Transactions 66, 595-600. http://dx.doi.org/10.3303/CET1866100

[5] Zhao B, Wei LK, Xu ZC, Zhou J, Ge XH. (2015). Photovoltaic accommodation capacity determination of actual feeder based on stochastic scenarios analysis with storage system considered. Automation of Electric Power Systems (9): 34-40. http://dx.doi.org/10.7500/AEPS20141124005

[6] Su JN, Wu LC, Nan HP. (2016). Research on the simulation of PV-ES microgrid based on PSCAD. Power System and Clean Energy (3): 149-153.

[7] Li QR, Zhang JC. (2016). Design of regulation strategy for voltage level at common coupling nodein distributed PV system with energy storages device. Modern $\begin{array}{llll}\text { Electric } & \text { Power } & 33(2) \text { : }\end{array}$ 
http://dx.doi.org/10.19725/j.cnki.1007-

2322.2016.02.006

[8] Du X, Zhou L, Guo K, Yang M, Liu Q, Shao NB. (2015). Static voltage stability analysis of large-scale photovoltaic plants. Power System Technology 39(12): 3427-3434.

[9] Li F, Zhang JC, Zhu LG. (2016). Control method of hybrid energy storage system for photovoltaic power balancing. Chinese Journal of Power Sources (2): 397472.

[10] Ye L, Chen Z, Zhao YN. (2014). A segmented smoothing control method for photovoltaic power considering Battery's state of charge. Power System Technology 38(7): 1812-1818.

[11] Wang W, Xue JH, Ye JL, Wang XH, Wu FB, Yang B. (2014). An optimization control design of battery energy storage based on SOC for leveling off the PV power fluctuation. Power System Protection and Control (2): 75-80.

[12] Li H, Li L. (2016). Application of fuzzy control in PVstorage distributed generation system. Review of Computer Engineering Studies 3(1): 11-15. http://dx.doi.org/10.18280/rces.030103

[13] Konstantinos FK, Alexandridis AT. (2015). Modular Control design and stability analysis of isolated PVsource/battery-storage distributed generation systems. IEEE Journal on Emerging and Selected Topics in Circuits and Systems 5(3): 372-382. http://dx.doi.org/10.1109/JETCAS.2015.2462172

[14] Alyami S, Wang Y, Wang C, Zhao J, Zhao B. (2014). Adaptive real power capping method for fair overvoltage regulation of distribution networks with high penetration of PV systems. IEEE Transactions on SmartGrid5(6):2729-2738. http://dx.doi.org/10.1109/TSG.2014.2330345
[15] Ike CC. (2018). Energy formulation for flexural torsional buckling of thin-walled column with open cross- section. Mathematical Modelling of Engineering Problems 5(2): 58-66. http://dx.doi.org/10.18280/mmep.050202

[16] Real time digital simulator (RTDS) manual. Available on:http://www.rtds.com/.

[17] Chen M, Rincon-Mora GA. (2006). Accurate electrical battery model capable of predicting runtime and $\mathrm{I}-\mathrm{V}$ performance. IEEE Transactions on Energy Conversion 21(2): 504-511.

[18] Li JL, Xiu XQ, Hui D. (2016). Key technology of energy storage system and its application in micro grid. BeiJing: China electric power press: 41-46.

[19] Cai GW, Kong LG, Pan C, Yang D, Sun Z. (2013). system modeling of Wind-PV-ES hybrid power system and its control strategy for grid-connected. Transactions of China Electrotechnical Society 28(9): 196-204.

[20] Liu GQ, Yuan Y, Wang M, Dai X, Lu XU. (2014). Energy storage capacity determining of PV plant considering economic cost. Renewable Energy Resources 32(1): 1-5.

[21] Wu YL, Sun YZ, Xu J, Peng X, Yang J. (2011). Determination methodology for energy storage capacity based on saturation control theory. Proceedings of the CSEE 31(22): 32-39. http://dx.doi.org/10.13334/j.02588013.pcsee.2011.22.006

[22] Wang YB, Cao R, Wang HY. (2015). Research on capacity ratio large-scaleon-grid PV/Battery station on mitigating PV power change. Acta Energiae Solarts Sinica 36(4): 1010-1017.

[23] Wang P. (2018). Design of a fast energy storage and energy conversion system for electric vehicle. Chemical Engineering Transactions 65: 469-474. http://dx.doi.org/10.3303/CET1865078 